DOI: 10.12731/2218-7405-2018-12-19-40

УДК 37.015.3

\title{
ЛИЧНОСТНЫЙ ПОТЕНЦИАЛ КАК ОСНОВА ЖИЗНЕСТОЙКОСТИ В СТУДЕНЧЕСКОМ ВОЗРАСТЕ
}

\author{
Боязитова И.В., Эркенова М.М.
}

Цель. Статья посвящена актуальной в условиях приоритетных задач высшего образования проблеме развития жизнестойкости как зрелой формы саморегуляции и нацелена на раскрытие особенностей личностного развития, оптимизирующего формирование жизнестойких убеждений в студенческом возрасте. Предметом анализа выступили жизнестойкость и личностные свойства студентов как личностного потенцииала саморегуляциии.

Методы и методология проведения работы. Для решения поставленных задач были использованы психодиагностические методbl, методы математической статистики. Основой исследования жизнестойкости выступила концептуальная модель саморегулящии и личностного потенцииала.

Результаты. В результате проведенного исследования установлено, что смысложизненные ориентации, внутренний локус контроля, самоактуализация, самодетерминация и самоэффективность личности, сопряженные с успешностью самоопределения в ичелях, с организациией ичеленаправленной деятельности, активным преодолением стрессогенных ситуаций, выступают личностным потенциилом, определяющим развитие жизнестойких убеждений в студенческом возрасте.

Область применения результатов. Результаты исследования могут быть применены в прочессе психолого-педагогического сопровождения студентов в условиях профессионального образования.

Ключевые слова: жизнестойкость; саморегуляиия; личностный потенциил; осмысленность жизни; самоактуализация; самодетерминация самоэффективность. 


\section{PERSONALITY POTENTIAL AS THE BASIS OF HARDINESS IN STUDENT AGE}

\section{Boyazitova I.V., Erkenova M.M.}

Purpose. The article is devoted to the topical problem of hardiness development as a mature form of self-regulation in the context of priority tasks of higher education and is aimed at revealing the features of personality development that optimizes the formation of life-sustaining beliefs in student age. The subjects of the analysis are hardiness and personality traits of students as personality potential of self-regulation.

Methods and methodology. Psychodiagnostic methods and mathematical statistics methods are used to solve these problems. The conceptual model of self-regulation and personality potential is taken as the basis of the study of hardiness.

Results. As the result of the study it is found that life orientations, the internal locus of control, self-actualization, self-determination and self-efficacy of an individual, associated with the success of self-determination in setting goals, organizing targeted activities, active overcoming of stressful situations are all the personality potential that determines the development of life-sustaining beliefs in student age.

Practical implications. The results of the study can be applied in the process of psychological and pedagogical support of students in terms of professional education.

Keywords: hardiness; self-regulation; personality potential; meaningfulness of life; self-actualization; self-determination; self-efficacy.

\section{Введение}

Социокультурные реалии современной жизни предъявляют высокие требования к потенциалу личности, ее внутренним ресурсам, способностям действовать в ситуации неопределенности, использовать активные формы саморегуляции, которые являются необходимыми условиями эффективного функционирования человека, 
формирования устойчивых жизненных стратегий, сохранения и укрепления его психологического здоровья.

Проблема развития саморегуляции актуализируется в студенческом возрасте, что обусловлено особенностями социального, личностного и профессионального становления на этапе поздней юности. С одной стороны, на данном возрастном этапе интенсивно формируется целостная идентичность, осуществляется личностное, моральное и профессиональное самоопределение, происходит становление «Я-концепции», возрастает потребность в самоутверждении и самореализации в разных сферах жизнедеятельности, что предполагает наличие устойчивой системы убеждений, мировоззренческой позиции и зрелой саморегуляции. С другой стороны, у молодого человека способность к саморегуляции, обеспечивающей целостность индивидуальности и самоорганизацию активности, ограничена возрастными особенностями, а при определенных условиях личностного развития, связанного с деиндивидуацией и аддикциями, ослабевает.

Развитие активных форм самоорганизации и саморазвития является приоритетной задачей высшего образования, стратегической целью которого является личностное и профессиональное становление студенческой молодежи.

Согласно положениям концепции саморегуляции и личностного потенциала Д.А. Леонтьева, в понятии «саморегуляция» объединены три регуляторные функции и три подсистемы личностного потенциала, которые взаимосвязаны и выступают как целостный процесс [8].

В основе функции самоопределения - способность выделять значимые, осмысленные цели, базирующиеся на ясных и четких мировоззренческих ценностях. Способы организации целенаправленной деятельности характеризуют функцию реализации, которые могут проявляться в упорстве, в отказе от цели низкого уровня или ее замене на менее масштабную цель, переключение на другую цель, в смене способов достижения цели. Функция сохранения ориентирована на предотвращение и противостояние неблагоприятным обстоятельствам. Опираясь на теорию саморегуляции Т. Хиггинса, 
Д.А. Леонтьев отмечает, что функции самоопределения и реализации ориентированы на достижение, а функция сохранения - на совладание со стрессовыми ситуациями; «причем эти две ориентации выступают основанием устойчивых жизненных стратегий» [там же, с. 123].

В концепции Д.А. Леонтьева три подсистемы личностного потенциала рассматриваются как потенциал саморегуляции. Потенциал самоопределения включает личностные переменные, сопряженные «с успешностью самоопределения в пространстве возможностей и выбора цели для последующей реализации»; в потенциал реализации входят личностные переменные, связанные «с организацией целенаправленной деятельности»; потенциал совладания охватывает личностные переменные, способствующие совладанию со стрессогенными факторами [там же, с. 121]. Подсистемы личностного потенциала представляют собой структурные образования, соизмеримые «с неспецифическими функциями саморегуляции, проявляющимися в самых разных ситуациях» [там же, с. 128].

В соответствии с представлениями Д.А. Леонтьева и Е.И. Рассказовой, одной из зрелых, сложных форм саморегуляции и «опорных переменных личностного потенциала» является жизнестойкость [9, с. 37].

Жизнестойкие убеждения в концептуальной модели С. Мади связаны с переживанием человека своих действий и событий жизнедеятельности, «как интересных и радостных (вовлеченность), как результатов личностного выбора и инициативы (контроль) и как важного стимула к усвоению нового (принятие риска)» [20, с. 85].

В исследованиях, проведенных зарубежными и отечественными психологами, установлено, что жизнестойкость, выступая «как один из ядерных компонентов личностного потенциала», опосредованно детерминирует успешность саморегуляции [8, с. 205]. В исследованиях отмечается, что «жизнестойкость связана с осмысленностью деятельности, резистентностью человека к потере смысла в деятельности и поиском нового смысла» [там же, с. 206]. Установлено, что высокие показатели жизнестойкости способствуют повышению регуляции деятельности и связаны с успешностью 
выполнения целенаправленной деятельности в разных сферах, как в условиях монотонной работы, так и в стрессовых ситуациях, что особенно значимо на этапах конкретизации целей, планирования в новых, трудных ситуациях при отсутствии гарантий на успех [23, $24,25,30]$. Согласно результатам исследования С. Кобейзы, жизнестойкость влияет на удовлетворенность работой во всех аспектах и связана с чувством автономии и свободы в принятии решений [28]. В исследованиях С. Мадди было выявлено, что выраженность жизнестойкости в целом и отдельных ее компонентов влияет на выбор копинг-стратегий, определяет активность в стрессогенных ситуациях $[8,18,20]$. Другими словами, жизнестойкость, являясь интегративной характеристикой личности, выступает потенциалом самоопределения, реализации, совладания, т.е. личностным потенциалом успешной саморегуляции.

Потенциал самоопределения в компоненте жизнестойкости «вовлеченность» проявляется в степени убежденности человека в том, что его активная включенность в происходящее имеет личную ценность, значимость, наполнена смыслом; в компоненте «контроль» связан с убежденностью в верности собственных решений и выбора жизненного пути; в компоненте «принятие риска» выражается в убеждениях, что события жизни, включая неожиданные, представляют для человека интерес, ценность и смысл в аспекте его развития.

Потенциал реализации в компоненте жизнестойкости «вовлеченность» проявляется в убежденности человека в том, что он способен при достижении результата проявлять активность и упорство; в компоненте «контроль» отражается на степени убежденности человека в том, что он способен влиять на результат деятельности, ставить труднодостижимые цели и собственными усилиями добиваться намеченного результата; в компоненте «принятие риска» обнаруживается в степени убежденности человека в готовности реально воплощать новые идеи, идти на риски.

Потенциал совладания в компоненте жизнестойкости «вовлеченность» проявляется в степени убежденности человека в том, что и при неблагоприятных обстоятельствах способен сохранять 
активность и интерес к жизни; в компоненте «контроль» выражается в степени убежденности в том, что способен и готов самостоятельно и уверенно разрешать, возникающие проблемы, несмотря на возможные поражения; в компоненте «принятие риска» связана с убеждениями в том, что все события жизни имеют ценность для развития и приобретения опыта.

В зарубежных и отечественных исследованиях подчеркивается, что развитие жизнестойкости зависит от многих психологических факторов, т.е. является зависимой переменной. Так, в работах С. Мадди раскрываются пять механизмов жизнестойкости, способствующие успешной саморегуляции: изменение субъективной оценки ситуации, создание мотивации к трансформационному совладанию, усиление иммунной реакции, поиск социальной поддержки, практики здорового образа жизни [7]. В ряде исследований обнаружена взаимосвязь жизнестойкости с такими психологическими переменными и позитивными характеристиками личности, как нейротизм, экстраверсия, открытость, дружелюбие, добросовестность, копингстратегии, чувство связности, оптимизм, резилентность, самоэффективность, религиозность, осмысленность жизни, толерантность к неопределенности и др. [9, 12, 15, 20, 21, 22, 26, 27, 30]. Однако, на сегодняшний день, таких исследований явно недостаточно. В предлагаемой статье представлены результаты исследования жизнестойкости у студенческой молодежи в рамках модели саморегуляции и личностного потенциала Д.А. Леонтьева.

Мы полагаем, что свойства личности, связанные с успешностью самоопределения в целях и смысложизненных ориентациях, с организацией целенаправленной деятельности, активным противостоянием и предотвращением неблагоприятных жизненных обстоятельств выступают личностным потенциалом, обеспечивающим развитие жизнестойких убеждений у студенческой молодежи. Определение личностных свойств как потенциала развития жизнестойкости и ее структурных компонентов явилось целью нашего исследования.

Теоретико-методологической основой нашего исследования 
выступили концепции жизнестойкости С. Мади, саморегуляции Ч. Карвера и М. Шейера, самодетерминации Э.Деси и Р. Райана, самоэффективности А. Бандуры, личностного потенциала саморегуляции Д.А. Леонтьева, Т.О. Гордеевой, О.Е Дергачевой, Е.Р. Калитеевской, Е.И. Рассказовой и др. [1, 2, 4, 5, 7, 18, 19, 29].

\section{Организация и методы исследования личностного} потенциала жизнестойкости в студенческом возрасте

В исследовании приняли участие студенты 1-3 курсов в количестве 98 человек Пятигорского государственного университета.

На первом этапе исследования была поставлена задача с помощью теста С. Мадди в адаптации Д.А. Леонтьева, Е.И. Рассказовой изучить особенности развития жизнестойких убеждений в студенческом возрасте. В результате проведенного исследования было выделено две группы студентов с полярным уровнем выраженности жизнестойкости. Первую группу составили студенты с высоким уровнем выраженности жизнестойкости в целом, согласованным взаимодействием ее отдельных компонентов (группа «СЖУ»). Вторая группа объединяла студентов со средним уровнем общего показателя жизнестойкости, несогласованным функционированием ее трех структурных компонентов (группа «НЖУ»).

На втором этапе задачей исследования выступило изучение особенностей развития личностных свойств как потенциала жизнестойкости в группах студентов «СЖУ» и «НЖУ». Программа психодиагностического исследования включала изучение осмысленности жизни и локуса контроля, личностных и каузальных ориентаций, самоэффективности на основе использования теста смысложизненных ориентаций Д.А. Леонтьева, самоактуализационного теста Э. Шострома, опросника каузальных ориентаций Д.А. Леонтьева, О.Е. Дергачевой, шкалы общей самоэффективности личности Р. Шварцера, М. Ерусалем.

На третьем этапе исследования решалась задача установления на основе статистического сравнительного анализа по t-критерию Стьюдента личностных переменных, определяющих развитие жиз- 
нестойких убеждений как потенциала саморегуляции в студенческом возрасте.

\section{Результаты исследования личностного потенциала жизнестойкости в студенческом возрасте}

В результате проведенного исследования было установлено, что большинство студентов (75\%) проявляют средний уровень развития жизнестойкости и непропорциональное соотношение ее структурных компонентов. Ограниченность развития компонента «вовлеченность» проявляется в том, что студенты испытывают чувство неудовлетворенности от результатов деятельности, трудности в определении ее смыслов и личной значимости, в поддержании активности при неблагоприятных обстоятельствах. Неразвитость компонента «контроль» выражается в том, что студенты проявляют неуверенность при осуществлении самостоятельных выборов и решений, не способны ставить труднодостижимые цели и собственными усилиями влиять на процесс и результат деятельности, демонстрируют сомнение и нерешительность при разрешении проблемных ситуаций. Более развитым и зрелым компонентом жизнестойкости является компонент «принятие риска», т.е. высока доля студентов, убежденных в том, что все события жизни, включая неблагоприятные, имеют ценность и смысл для собственного развития и приобретения опыта, что способны и готовы воплощать в жизнь новые идеи и дела даже без твердых гарантий успеха. Ограниченность развития жизнестойких убеждений актуализирует проблему развития жизнестойкости как активной формы самоорганизации и саморазвития в студенческом возрасте.

Анализ результатов исследования позволил выделить следующие особенности личностного развития студентов с согласованным (группа «НЖУ») и несогласованным (группа «НЖУ») функционированием структурных компонентов жизнестойкости.

Согласно концепции Д.А. Леонтьева, смысловые образования являются ядром личности и выступают регуляторами деятельности человека [7]. Структурными составляющими осмысленности 
жизни являются смысложизненные ориентации и внутренний локус контроля. Общая осмысленность жизни выступает производным индикатором смысловых ориентиров и преобладающего локуса управления. Смысложизненные ориентации включают три категории, соотносимые с целью жизни (субшкала «Цели в жизни»), процессом жизни (субшкала «Процесс жизни») и результатом жизнедеятельности (субшкала «Результативность жизни»). Внутренний локус контроля определяет веру в собственную способность контролировать события, строить свою жизнь в соответствии с собственными целями и смыслами (субшкала «Локус контроля - Я») и отражает общее мировоззренческое убеждение человека в том, что контроль и управление жизнью возможно (субшкала «Локус контроля - жизнь»). По мнению В.Э. Чудновского, при оптимальном уровне осмысленности жизни человек приобретает способность учитывать реалии сегодняшнего дня, преобразовывать обстоятельства и собственное поведение в ходе реализации своей «главной линии жизни» [11, с. 240].

Проведенный статистический анализ показал, что по всем показателям смысложизненных ориентаций наблюдаются различия высокой степени достоверности $(\mathrm{p}<0,001)$ между группой студентов «СЖУ» и «НЖУ». Студенты с высоким уровнем жизнестойкости и согласованным взаимодействием ее отдельных компонентов в большей степени, чем студенты со средним уровнем и несогласованным функционированием ее структурных компонентов, проявляют определенность жизненных целей, смыслов, взглядов, живут настоящим и будущим, испытывают чувство удовлетворенности самореализацией, показывают способность самостоятельно организовывать свою жизнь, управлять событиями жизни. Итак, установлено, что развитие смысловых ориентиров и локуса контроля детерминирует формирование жизнестойких убеждений в студенческом возрасте.

Мотивационным фактором развития личностных потенций выступает самоактуализация личности, которая осуществляется на основе сознательно определившихся целей в процессе самореализации и выработанных способов их достижения. Самоактуализация 
и самореализация рассматривается как два неразрывных и единых процесса развития человеческого потенциала, результатом которого является самоактуализировавшаяся личность. Два основных параметра характеризуют самоактуализирующеюся личность: компетентность во времени «Ориентация во времени», вектор направленности личности «Поддержка»; шесть блоков дополнительных параметров: ценностей, чувств, самовосприятия, концепции человек, межличностной чувствительности, отношения к познанию.

При анализе развития переменных самоактуализации личности между двумя группами студентов с разным уровнем жизнестойкости были выявлены статистически значимые различия по основным показателям «Ориентация во времени» $(\mathrm{p}<0,001)$ и «Поддержка» $(\mathrm{p}<0,001)$. Статистически значимые различия были установлены и по дополнительным показателям блока ценностей - «Ценностные ориентации» $(\mathrm{p}<0,001)$, блока чувств - «Спонтанность» $(\mathrm{p}<0,01)$, блока самовосприятия - «Самоуважение» $(\mathrm{p}<0,001)$, блока концепции человека - «Синергия» $(\mathrm{p}<0,05)$.

У студентов группы «СЖУ» компетентность во времени проявляется в способности связывать жизненные цели с текущей деятельностью, опираясь на прошлый опыт, видеть свою жизнь целостной в неразрывном единстве прошлого, настоящего и будущего, осознавая смысл и значимость совершаемых действий. Студенты группы «НЖУ» обладают более низким уровнем компетентности по отношению ко времени, их жизнедеятельность не связана с целями настоящего времени, а в большей степени ориентирована прошлым опытом или будущими целями и планами.

Студенты группы «СЖУ» имеют более высокие баллы по шкале «Поддержка», т.е. в большей мере в своем поведении руководствуются собственными целями и убеждениями, внутренними принципами и мотивацией по сравнению с группой студентов «НЖУ», наиболее подверженных влиянию внешних обстоятельств, ориентированных на поддержку извне, мнение и одобрение других. Иначе говоря, поведение студентов группы «СЖУ» направляется изнутри, а группы «НЖУ» - извне. 
Блок ценностей включает две шкалы: шкала «Ценностные ориентации» - измеряет, в какой степени человек в своем поведении, руководствуется своими ценностями и идеалами; шкала «Гибкость поведения» характеризует степень гибкости поведения человека в реализации своих ценностей. Статистическое сравнение групп студентов «СЖУ» «НЖУ» выявило различие только по шкале «Ценностные ориентации». Большинство студентов группы «СЖУ» действуют, руководствуясь собственными ценностями, взглядами, желаниями в отличие от студентов группы «НЖУ», не разделяющих ценности самоактуализирующейся личности.

Шкала «Сензитивность», отражающая степень рефлексивности собственных чувств, потребностей и шкала «Спонтанность», определяющая способность человека действовать и выражать чувства спонтанно и непосредственно, образуют блок чувств. Различия между двумя группами выявлены только по шкале «Спонтанность»: для студентов группы «СЖУ» свойственны высокие значения, что свидетельствует о способности личности открыто выражать свои мысли и чувства в различных обстоятельствах; для студентов группы «НЖУ» характерны низкие значения, что проявляется в закрытости, в заранее продуманных действиях, в невозможности быть естественным.

Статистическое сравнение показателей, составляющих блок самовосприятия, т.е. шкалы «Самоуважение», измеряющей степень уважения человека себя с учетом собственных достоинств и шкалы «Самопринятие», выражающей способность человека принимать себя безусловно и вне зависимости от самооценки, установило различие между группой студентов «СЖУ» и группой студентов «НЖУ» по одной шкале «Самоуважение». Студенты группы «СЖУ» в большей степени, чем в группе студентов «НЖУ» проявляют к себе чувство самоуважения, высоко ценят себя, имея на это объективные основания.

Дальнейший анализ данных показывает, что значительное количество респондентов в группе студентов «СЖУ» в сравнении с группой студентов «НЖУ», имеют высокие баллы по шкале «Синергия» 
(блок концепции человека), что свидетельствует о преимуществе данной группы в развитии способности к целостному восприятию окружающего мира, в понимании единства и связи противоположностей. По второй шкале блока концепции человека «Представления о природе человека», как и по шкалам «Контактность», «Принятие агрессии» блока межличностной чувствительности, «Познавательные потребности», «Креативность» блока отношения к познанию статистически значимые различия между группами студентов «СЖУ» и «НЖУ» были не выявлены.

Полученные результаты позволяют сделать вывод о том, что жизнестойкость сопряжена с переменными самоактуализации личности. Студенты с высоким уровнем жизнестойкости и согласованным взаимодействием ее отдельных компонентов демонстрируют в целом высокий уровень самоактуализации. Студенты со средним уровнем и несогласованным функционированием ее структурных компонентов испытывают трудности в самореализации.

Основой, стержнем личностного потенциала выступает автономия как зрелая форма саморегуляции, как «способ индивидуального участия в мире..., направленный в итоге на идею утверждения жизни» [17, с. 1].

Автономная личность - самодетерминированная личность, имеющая собственную мировоззренческую позицию «в контексте «системы координат» ценностей», «базирующихся на общечеловеческой культуре»; действующая на основе осознанного самостоятельного выбора, рефлексии собственных потребностей с учетом внешних объективных обстоятельств [3, с. 269].

В современных исследованиях «самодетерминированная активность субъекта становится центральной координатой автономии» $[2,4,5,6,10,29]$.

Доказано, что уровень личностной автономии определяет направленность и зрелость личностного развития, выступает показателем психической устойчивости и психологического здоровья, влияет на мотивацию и эффективность деятельности, восприятие стрессогенных факторов [16]. 
Согласно представлениям Э. Деси и Р. Райана, степень самодетерминированного поведения зависит от особенностей развития внутренней (автономной), внешней или безличной каузальных ориентаций и их соотношения.

В своем исследовании О.Е. Дергачева, Д.А. Леонтьев отмечают, что автономная каузальная ориентация базируется на внутренней мотивационной субсистеме - на внутренних ценностях и интереcax, на чувстве самодетерминации и компетентности. Внешняя каузальная ориентация характеризуется ориентацией на внешний контроль, стремлением к сверхдостижениям, недостаточной самодетерминацией. Безличная каузальная ориентация отличается преобладанием амотивирующей субсистемы, которая проявляется в отсутствии активности и некоторым проявлением внешней мотивирующей субсистемы, что проявляется в симптомах «выученной беспомощности [8].

В результате сравнительного анализа развития каузальных ориентаций у студентов с полярным уровнем развития жизнестойких убеждений были установлены статистически значимые различия по шкале «Автономия» $(\mathrm{p}<0,05)$ и «Безличной шкале» $(\mathrm{p}<0,05)$ и не выявлены по шкале «Контроль». У студентов группы «СЖУ» в большей степени развито чувство компетентности, самодетерминации и в меньшей степени проявляются чувства беспомощности, чем у студентов группы «НЖУ». Внешняя каузальная ориентации в обеих группах достаточно интенсивно проявляется, что свидетельствует об активной адаптации студентов к внешним требованиям социальной ситуации развития.

Однако, обращают на себя внимание не столько результаты статистического сравнения, сколько соотношение типов каузальных ориентаций в группе «СЖУ» и «НЖУ». Для группы студентов с согласованным функционированием структурных компонентов («СЖУ») характерно доминирование автономной и внешней каузальных ориентаций, что является признаком успешного разрешения конфликтов, связанных с компетентностью и самодетерминацией. Для группы студентов с несогласованным функционированием 
структурных компонентов («НЖУ») типично преобладание автономной и безличной каузальных ориентаций, что свидетельствует о несоответствующем решении конфликтов как самодетерминации, так и компетентности.

Важно подчеркнуть, что согласованность во взаимодействии внутренней и внешней каузальных ориентаций обеспечивает эффективную адаптацию к внешним условиям среды. Д.А. Леонтьев подчеркивал: «Возможно, именно в гармоничной интеграции внешней и внутренней каузальной ориентации, а не в их противопоставлении, и заключен ответ на вопрос об оптимальной структуре саморегуляции человеческой жизнедеятельности».

Результаты статистического анализа позволяют сделать вывод о значимом влиянии типа каузальных ориентаций на проявление жизнестойкости в целом и ее отдельных компонентов в студенческом возрасте. Согласованность во взаимодействии автономной и внешней каузальных ориентаций способствует повышению жизнестойкости в целом и обеспечивает оптимальное развитие таких компонентов, как «вовлеченность» и «контроль». При этом, на этапе студенчества особое влияние на проявление жизнестойкости имеет внутренняя автономная каузальная ориентация, которая детерминирует развитие жизнестойких убеждений, способствует повышению осмысленности, удовлетворенности деятельностью, поддержанию уверенности и активности при неблагоприятных жизненных обстоятельствах, при осуществлении самостоятельных выборов и решений.

Одной из личностных переменных, соотносимых с жизнестойкостью, является самоэффективность, которая определяется как система представлений о своих возможностях и способностях, как вера в собственную эффективность $[8,13,14]$.

В современных исследованиях отмечается, что самоэффективность, или оптимистичная вера в свой потенциал, оказывает существенное влияние на мотивацию, целеполагание, является предиктором успешности в деятельности и социального функционирования, ослабляет действие стрессогенных факторов, играет значимую роль в инициации и поддержании здорового образа жизни [8]. 
Другими словами, представления, связанные с эффективностью личности, сопряжены с регуляторной активностью человека в условиях достижений и преодоления неблагоприятных жизненных обстоятельств.

В результате проведенного статистического сравнительного анализа выявлено различие высокой степени достоверности $(\mathrm{p}<0,001)$ по показателю «Самоэффективность» между группой студентов «СЖУ» и «НЖУ». Было установлено, что в группе студентов «СЖУ» большинство испытуемых проявляют высокий уровень самоэффективности (62,5\%). В группе студентов «НЖУ» треть испытуемых имеет низкий уровень самоэффективности. У студентов группы «СЖУ» в большей степени, чем у студентов группы «НЖУ» выражена уверенность в собственной эффективности в различных видах деятельности, способности успешно достигать, намеченных целей, и улучшать свои достижения; развито умение справляться с трудностями, не поддаваться неудачам, критике, отвержениям и собственным сомнениям. Студенты группы «НЖУ» проявляют неуверенность в своих способностях достигать целей и успешных результатов деятельности, преодолевать трудности, а также чувствительность к неудачам и неприятностям. Результаты сравнительного анализа позволяют говорить о значимом влиянии представлений, связанных с эффективностью личности, на формирование жизнестойких убеждений в студенческом возрасте.

Самоэффективность, как вера человека в свою способность справиться с деятельностью, ведущей к достижению необходимого результата, определяет активность, готовность к изменению окружающей действительности, что в свою очередь, способствует развитию жизнестойких убеждений. С одной стороны, вера в себя порождает активность, а с другой, только в деятельности человек может раскрыть свой потенциал и быть успешным, что, будет способствовать готовности преодолевать трудные жизненные обстоятельства. Другими словами, вера человека в свою эффективность, существенно определяет формирование жизнестойкости в целом и ее отдельных компонентов в студенческом возрасте. 


\section{Заключение}

Результаты исследования позволяют сделать выводы о связи жизнестойкости и ее компонентов с личностными свойствами, выступающими личностным потенциалом развития жизнестойкости у студенческой молодежи.

Установлено, что развитие жизнестойких убеждений в студенческом возрасте зависит от свойств личности, связанных с успешностью самоопределения в целях, с организацией целенаправленной деятельности, активным противостоянием неблагоприятным обстоятельствам. Студенты с высоким уровнем жизнестойкости и согласованным взаимодействием ее отдельных компонентов в сравнении с группой студентов со средним уровнем и несогласованным функционированием ее структурных компонентов, характеризуются более высоким уровнем:

- осмысленности жизни, что проявляется в определенности жизненных целей, связанных с настоящим временем, в чувстве удовлетворенности самореализацией, в способности самостоятельно организовывать и управлять процессами жизнедеятельности;

- самоактуализации, что выражается во внутренней направленности личности, в чувстве самоуважения на основе объективных фактов, способности связывать жизнь с целями настоящего времени, действовать в различных обстоятельствах, целостно воспринимать окружающий мир с позиции единства и связи противоположностей;

- самодетерминации и компетентности, что проявляется в согласованном взаимодействии автономной и внешней каузальных ориентаций, в интеграции внутренних ценностей, интересов и внешнего контроля;

- самоэффективности, т.е. уверенности в собственной эффективности, в своих возможностях и способностях продуктивно выполнять различные виды деятельности, достигать, поставленных целей, упорно продолжать свое дело и улучшать результаты, преодолевая трудности.

Смысложизненные ориентации, внутренний локус контроля, самоактуализация, самодетерминация и самоэффективность лично- 
сти выступают личностным потенциалом, определяющим развитие жизнестойких убеждений в студенческом возрасте. Развитие личностных свойств, оптимизирующих процессы самоорганизации и саморазвития, является главным условием обеспечения успешной саморегуляции студентов.

Информация о конфликте интересов. Авторы заявляют об отсутствии конфликта интересов.

\section{Список литературы}

1. Гордеева Т.О. Психология мотивации достижения. М.: Смысл; Издательский центр «Академия», 2006. 336 с.

2. Дергачева О.Е. Автономия и самодетерминация в психологии мотивации: Теория Э. Деси и Р. Райана // Современная психология мотивации / Под ред. Д.А. Леонтьева. М.: Смысл, 2002. С. 103-121.

3. Зинченко В.П., Моргунов Е.Б. Человек развивающийся. Очерки российской психологии. М.: Тривола, 1994. 304 с.

4. Калитеевская Е.Р., Леонтьев Д.А. Пути становления самодетерминации личности в подростковом возрасте // Вопр. психол. 2006. № 3. С. 49-55.

5. Калитеевская Е.Р., Леонтьев Д.А., Осин Е.Н., Бородкина И.В. Смысл, адаптация и самодетерминация у подростков // Вопр. психол. 2007. № 2. С. 68-79.

6. Леонтьев Д.А. Психология свободы: к постановке проблемы самодетерминации личности // Психол. журн. 2000а. Т. 21. № 1. С. 15-25.

7. Леонтьев Д.А. Психология смысла: природа, строение и динамика смысловой реальности. 2-е, испр.изд. М.: Смысл, 2003. С. 107-130, 178-266.

8. Личностный потенциал: структура и диагностика / Под ред. Д.А. Леонтьева. М.: Смысл, 2011. 675 с.

9. Леонтьев Д.А., Рассказова Е.И. Тест жизнестойкости. М.: Смысл, 2006. $63 \mathrm{c}$.

10. Чирков В. И. Самодетерминация и внутренняя мотивация поведения человека // Вопр. психол. 1996. № 3. С. 116-132.

11. Чудновский В.Э. Становление личности и проблема смысла жизни: Избранные труды. М.: Изд-во Московского психолого-социального института, 2006. 768 с. 
12. Antonovsky A. The Sense of Coherence as a Determinant of Health // Behavioral Health: a Handbook of Health Enhancement and Disease Prevention / J. D. Matarazzo, N. Miller (Eds.). N.Y.: Wiley, 1984, pp. 194-202.

13. Bandura A. The social foundations of thought and action: A social cognitive theory. Englewood Cliffs (NJ): Prentice Hall, 1986.

14. Bandura A. Self-Efficacy: Toward a Unifying Theory of Behavior Change // Psychological Review. 1977. Vol. 84, pp. 191-215.

15. Bengel J., Strittmatter R., Willman H. What Keeps People Healthy? The Current State of Discussion and the Relevance of Antonovsky's Salutogenic Model of Health // Research and Practice of Health Promotion. 1999. Vol. 4.

16. Deci E.L. The psychology of self-determination. Toronto: Lexington books, 1980.

17. Gabanska J. Autonomy of the individual in the developmental and axiological perspective // The polish quarterly of developmental psychology. 1995. Vol. 1. № 1-4, pp. 1-11.

18. Carver C., Scheier M. On the Self-Regulation of Behavior. N.Y.: Cambridge University Press, 1998.

19. Maddi S. Dispositional Hardiness in Health and Effectiveness // Encyclopedia of Mental Health / Friedman H. S. (Ed.). San Diego (CA): Academic Press, 1998b, pp. 323-335.

20. Maddi S. The Personality Construct of Hardiness: Effects on Experiencing, Coping and Strain // Consulting Psychology Journal: Practice and Research. 1999. Vol. 51. № 2, pp. 83-94.

21. Maddi S. The Role of Hardiness and Religiosity in Depression and Anger // International Journal of Existential Psychology \& Psychotherapy. 2004b. Vol. 1. № 1, pp. 38-49.

22. Maddi S., Harvey R. Hardiness Considered Across Cultures // Handbook of Multicultural Perspectives on Stress and Coping / P. T. P. Wong, L.C. J. Wong (Eds). N.Y.: Springer, 2005, pp. 403-420.

23. Maddi S., Harvey R., Khoshaba D., LuJ., Persico M., Brow M. The Personality Construct of Hardiness III: Relationships with Repression, Innovativeness, Authoritarianism and Performance // Journal of Personality. 2006. Vol. 74. № 32, pp. 575-598. 
24. Maddi S., Harvey R., Resurreccion R., Giatras C., Raganold S. Hardiness as a performance enhancer in firefighters // International Journal of Fire Service Leadership and Management. 2007. Vol. 1, pp. 3-9.

25. Maddi S., Hess M. Personality Hardiness and Success in Basketball // Journal of Sport Psychology. 1992. Vol. 23, pp. 360-368.

26. Maddi S., Hightower M. Hardiness and Optimism as Expressed in Coping Patterns // Consulting Psychology Journal: Practice and Research. 1999. Vol. 51. № 2, pp. 95-105.

27. Maddi S., Khoshaba D. Resilience at Work. N.Y.: American Management Association, 2005.

28. Maddi S., Kobasa S. The Hardy Executive: Health under Stress. Homewood (IL): Dow Jones-Irwin. 1984.

29. Ryan R.M., Deci E.L. Self-determination theory and the facilitation of intrinsic motivation, social development and well-being // American psychologist. 2000. Vol. 55. № 1, pp. 68-78.

30. Sansone S., Wiebe D., Morgan C. Self-Regulating Interest: The Moderating Role of Hardiness and conscientiousness // Journal of Personality. 1999. Vol. 67. № 4, pp. 701-732.

\section{References}

1. Gordeeva T.O., Psikhologiya motivatsii dostizheniya [ Psychology of achievement motivation]. Moscow, Smysl Publ., Akademiya Publ., 2006. 336 p. (in Russian)

2. Dergacheva O.E., Avtonomiya i samodeterminatsiya v psikhologii motivatsii: Teoriya E. Desi i R. Rayana [Autonomy and self-determination in psychology of motivation: theory of E. Deci and R. Ryan ], Sovremennaya psikhologiya motivatsii [Modern psychology of motivation] / ed. Leontiev D.A., Moscow, Smysl Publ., 2002. 103-121 p. (in Russian)

3. Zinchenko V.P., Morgunov E.B. Chelovek razvivayushchiysya. Ocherki rossiyskoy psikhologii [The developing human being. Essays of Russian psychology]. Moscow, Trivola Publ., 1994. 304 p. (in Russian)

4. Kaliteevskaya E.R., Leontiev D.A. Puti stanovleniya samodeterminatsii lichnosti v podrostkovom vozraste [The ways of formation of personality self-determination in adolescence]. Voprosy psikhologii, 2006, no.3, pp. 49-55 (in Russian) 
5. Kaliteevskaya E.R., Leontiev D.A., Osin E.N., Borodkina I.V. Smysl, adaptatsiya i samodeterminatsiya u podrostkov [The sense, adaptation, and self-determination of adolescents]. Voprosy psikhologii, 2007, no. 2, pp. 68-79 (in Russian)

6. Leontiev D.A. Psikhologiya svobody: k postanovke problemy samodeterminatsii lichnosti [Psychology of freedom: statement of the problem of self-determination of personality]. Psikhologicheskiy zhurnal, 2000a., Vol. 21, no. 1, pp. 15-25 (in Russian)

7. Leontiev D.A., Psikhologiya smysla: priroda, stroenie i dinamika smyslovoy real'nosti [Psychology of meaning: nature, structure and dynamics of semantic reality]. $2^{\text {nd }}$ ed., Moscow, Smysl Publ., 2003, pp 107-130, pp. 178-266 (in Russian)

8. Lichnostnyy potentsial: struktura i diagnostika [Personal potential: structure and diagnostics]. ed. D. Leontiev. M., Smysl Publ., 2011. 675 p. (in Russian)

9. Leontiev D.A., Rasskazova E.I. Test zhiznestoykosti [Test of hardiness]. Moscow, Smysl Publ., 2006. 63 p. (in Russian)

10. Chirkov V.I. Samodeterminatsiya i vnutrennyaya motivatsiya povedeniya cheloveka [Self-determination and inner motivation of human behavior]. Voprosy psikhologii, 1996, no. 3, pp. 116-132.(in Russian)

11. Chudnovsky V.E. Stanovlenie lichnosti i problema smysla zhizni: Izbrannye trudy [Formation of personality and the problem of the meaning of life: Selected works]. Moscow, Moscow Psychology-Social Institute Publ. 2006. P. 768.

12. Antonovsky A. The Sense of Coherence as a Determinant of Health. Behavioral Health: a Handbook of Health Enhancement and Disease Prevention / J.D. Matarazzo, N. Miller (Eds.). N.Y.: Wiley, 1984, pp. 194-202.

13. Bandura A. The social foundations of thought and action: A social cognitive theory. Englewood Cliffs (NJ): Prentice Hall, 1986.

14. Bandura A. Self-Efficacy: Toward a Unifying Theory of Behavior Change. Psychological Review. 1977. Vol. 84, pp. 191-215.

15. Bengel J., Strittmatter R., Willman H. What Keeps People Healthy? The Current State of Discussion and the Relevance of Antonovsky's Salutogenic Model of Health. Research and Practice of Health Promotion. 1999. Vol. 4. 
16. Deci E.L. The psychology of self-determination. Toronto: Lexington books, 1980.

17. Gabanska J. Autonomy of the individual in the developmental and axiological perspective. The polish quarterly of developmental psychology. 1995. Vol. 1. № 1-4, pp. 1-11.

18. Carver C., Scheier M. On the Self-Regulation of Behavior. N.Y.: Cambridge University Press, 1998.

19. Maddi S. Dispositional Hardiness in Health and Effectiveness. Encyclopedia of Mental Health / Friedman H.S. (Ed.). San Diego (CA): Academic Press, 1998b, pp. 323-335.

20. Maddi S. The Personality Construct of Hardiness: Effects on Experiencing, Coping and Strain. Consulting Psychology Journal: Practice and Research. 1999. Vol. 51. № 2, pp. 83-94.

21. Maddi S. The Role of Hardiness and Religiosity in Depression and Anger. International Journal of Existential Psychology \& Psychotherapy. 2004b. Vol. 1. № 1, pp. 38-49.

22. Maddi S., Harvey R. Hardiness Considered Across Cultures. Handbook of Multicultural Perspectives on Stress and Coping / P. T. P. Wong, L. C. J. Wong (Eds). N.Y.: Springer, 2005, pp. 403-420.

23. Maddi S., Harvey R., Khoshaba D., Lu J., Persico M., Brow M. The Personality Construct of Hardiness III: Relationships with Repression, Innovativeness, Authoritarianism and Performance. Journal of Personality. 2006. Vol. 74. № 32, pp. 575-598.

24.Maddi S., Harvey R., Resurreccion R., Giatras C., Raganold S. Hardiness as a performance enhancer in firefighters. International Journal of Fire Service Leadership and Management. 2007. Vol. 1, pp. 3-9.

25. Maddi S., Hess M. Personality Hardiness and Success in Basketball. Journal of Sport Psychology. 1992. Vol. 23, pp. 360-368.

26. Maddi S., Hightower M. Hardiness and Optimism as Expressed in Coping Patterns. Consulting Psychology Journal: Practice and Research. 1999. Vol. 51. № 2, pp. 95-105.

27. Maddi S., Khoshaba D. Resilience at Work. N.Y.: American Management Association, 2005.

28. Maddi S., Kobasa S. The Hardy Executive: Health under Stress. Homewood (IL): Dow Jones-Irwin. 1984. 
29. Ryan R.M., Deci E.L. Self-determination theory and the facilitation of intrinsic motivation, social development and well-being. American psychologist. 2000. Vol. 55. № 1, pp. 68-78.

30. Sansone S., Wiebe D., Morgan C. Self-Regulating Interest: The Moderating Role of Hardiness and conscientiousness. Journal of Personality. 1999. Vol. 67. № 4, pp. 701-732.

\section{ДАННЫЕ ОБ АВТОРАХ}

Боязитова Ирина Валерьевна, профессор кафедры общей и педагогической психологии, доктор психологических наук Пятигорский государственный университет пр. Калинина 9, г. Пятигорск, Ставропольский край, 357500 , Российская Федерация biv_pglu@mail.ru

Эркенова Мариям Мустафаевна, доцент кафедры общей и педагогической психологии, кандидат психологических наук Пятигорский государственный университет пр. Калинина 9, г. Пятигорск, Ставропольский край, 357500 , Российская Федерачия mariyam.ps@mail.ru

\section{DATA ABOUT THE AUTHORS}

Boyazitova Irina Valerevna, Professor of the Department of General and Pedagogical Psychology, Doctor of Psychological Science Pyatigorsk State University 9, Kalinin Ave., Pyatigorsk, Stavropol Krai, 357500, Russian Federation biv_pglu@mail.ru

Erkenova Mariyam Mustafaevna, Associate Professor at the Department of General and Pedagogical Psychology, PhD in Psychology Pyatigorsk State University 9, Kalinin Ave., Pyatigorsk, Stavropol Krai, 357500, Russian Federation mariyam.ps@mail.ru 